\title{
ano fáustico de 2019
}

\section{Rafael Rocca dos Santos ${ }^{I}$}

O ANO DE 2019 viu no Brasil o lançamento de diversas obras, sendo textos literários e críticos, tratando de Fausto em suas diversas manifestações e suas diversas abordagens. Citamos, como exemplo, o volume 96 desta revista do Instituto de Estudos Avançados da USP, que dedicou uma seção a Johann Wolfgang von Goethe e, entre os textos ali publicados, encontram-se análises novas tanto da obra Fausto como de aspectos relacionados à tradição fáustica, como o texto de Michael Jaeger. O organizador desse dossiê publicou seu volume $A$ dupla noite das tílias: história e natureza no Fausto de Goethe (Mazzari, 2019), que trata da natureza na tragédia de Goethe, relacionando-a a diversos aspectos analíticos, entre eles questões de teoria literária (como os conceitos de símbolo e alegoria) e políticas (o processo colonizador).

Esses dois exemplos permitem afirmar que, longe de esgotada, a tradição fáustica continua a dar subsídios e ser ponto de partida para análises atuais da sociedade e de sua manifestação na literatura, confirmando a ideia de Italo Calvino acerca do clássico. $\mathrm{O}$ interesse pelo tema "Fausto" segue vivo e atual, na medida em que as bases daquela tradição são uma parte relevante da individualidade atual: entre elas, a busca pelo imediato, a ânsia de abarcar o conhecimento total (e poderíamos dizer a vigilância total), a vontade de poder e de dominação, a subjugação da natureza, como vimos em episódios recentes no país. Essa tradição, no entanto, passou por diversas mudanças e adquiriu nuances conforme o decorrer dos séculos, à medida que se transformava o pensamento das sociedades (por exemplo, do caráter religioso da regência da vida à secularização, da condenação por pecados à redenção, do coletivismo ao individualismo, entre outros).

Tais bases da tradição fáustica originam-se de um personagem de carne e osso que viveu na Alemanha entre os séculos XV e XVI e sobre quem se escreveu uma obra anônima, destinada à educação da base protestante, como forma de demonstrar a essa população cristã as consequências de se entregar a espíritos duvidosos para alcançar uma sabedoria sobre o mundo que deveria permanecer oculta. Esse texto foi impresso por um editor alemão chamado Johann Spies em 1587, publicado na Feira do Livro de Frankfurt daquele ano, e que agora finalmente se oferece ao leitor brasileiro em duas traduções: História do Doutor Johann Fausto, publicado pela editora Filocalia (Anônimo, 2019), e como segundo texto de uma coletânea mais ampla intitulada A trágica história do Doutor Fausto, tradução brasileira da peça de Christopher Marlowe (2018). As duas obras podem ser lidas em complementaridade, motivo pelo qual se escolheu iniciar pela publicação da editora Filocalia.

Traduzida, organizada e comentada por Magali Moura, professora de língua e literatura alemã da Universidade Estadual do Rio de Janeiro, sua versão do texto anônimo do século XVI traz uma gama de comentários, sendo um dos principais trunfos da edição. Nota-se de partida que a pesquisa levada a cabo por 
Moura tem uma profundidade ímpar e permite que o leitor moderno se inteire dos pormenores do texto fáustico, por vezes de difícil acesso dada a distância temporal, ampliando a compreensão tanto da época de escrita do texto quanto dele em si.

A tradução se baseia nas principais edições publicadas em língua alemã (qualidade compartilhada pela edição da Ateliê), com uma justificativa plausível pela escolha do texto-base. Ressalta-se a importância do tratamento das questões que envolvem o mito fáustico já nas primeiras notas ao texto, que, em linguagem simples que não carece de complexidade, são apresentadas ao leitor os principais fundamentos que permitirão uma compreensão mais ampla do restante da obra. O preciosismo e o detalhamento das notas, ao invés de se tornar um estorvo à leitura do texto em si, flui de maneira agradável ao leitor, ainda que, por decisão editorial, tenha-se posicionado as notas ao final de cada capítulo e não em rodapé, nem ao final do volume, o que compromete uma melhor fruição da obra enquanto livro.

Para além da publicação do texto em si, cuja tradução é fluida, a maior qualidade do livro está no ensaio crítico publicado após o texto. Nele, Magali Moura traça um panorama amplo e detalhado sobre o homem Fausto e o surgimento da tradição literária, identificando já nos primórdios os temas que foram posteriormente trabalhados e retrabalhados por outros autores, entre eles Goethe em sua obra magna. O texto do ensaio traz informações antes não disponíveis em português, tais como a tradução da carta de Johannes Tritheim a Johannes Virdung (p.219-220), um dos documentos principais sobre as atividades do
Fausto-homem por testemunhas de época; no mesmo sentido, têm-se, à página 223, a tradução dos registros municipais de Ingolstadt e Nuremberg que atestam a presença de Fausto nesses locais, o que permite traçar uma trajetória do que se viu e ouviu dizer sobre esse obscuro personagem. Conversas de Lutero à mesa (as Tischreden) também são abordadas, traduzidas e comentadas, o que enriquece sobremaneira o ensaio, que, por seu teor crítico e documental, pode ser lido tanto por estudiosos quanto por interessados em geral.

Em seguida, a autora identifica e comenta os principais traços da composição da temática fáustica que se originou a partir da publicação do livro anônimo. A relação da percepção do diabo em meio à sociedade e sua transformação pré e pós-Renascimento e Reforma; a curiosidade como elemento perturbador da ordem religiosa e social, relacionando-a a condenações por transgressão à lei religiosa; ${ }^{1}$ e o uso do humor e do riso como elemento de aproximação e identificação ao leitor da época e aos propósitos da publicação do livro são os temas principais do ensaio da autora, além da história do texto e de seu estabelecimento nos anos após sua publicação original em 1587.

A análise da autora se baseia em fontes recentes e discussões atuais, que podem facilmente ser extrapoladas pelo leitor em analogia com a situação atual da sociedade, o que torna a leitura do texto anônimo e do ensaio crítico proveitoso para uma compreensão mais fundamentada do funcionamento dos mecanismos de controle da sociedade pelas instituições religiosas. Essa possibilidade de atualização do tema, aliada à leitura das obras mencionadas no início deste texto, 
justifica a importância que deve ser atribuída à publicação da narrativa primeira da profícua tradição fáustica.

Logo após publicada, a história anônima de Fausto foi traduzida para o inglês, sem uma data consensualmente definida entre os especialistas (c. 15881592), e publicada na Inglaterra com modificações e alterações do tradutor P. H. Cavalheiro, conforme era corrente nas traduções da época. $\mathrm{O}$ "livro inglês do Fausto" atraiu a atenção de Christopher Marlowe (2018), que escreveu a peça A trágica história do Doutor Fausto, oferecida ao leitor brasileiro na bela edição da Ateliê Editorial, com tradução e notas de Luís Bueno e Caetano W. Galindo.

A peça, provavelmente a primeira tradução brasileira, conforme Luís Bueno afirma em seu texto introdutório, é apresentada em edição bilíngue, permitindo ao leitor acompanhar o texto original ao lado da versão em português. A tradução, conforme comentam os tradutores da obra, tem o propósito de ser lida individualmente e foi pensada também para o aproveitamento no teatro, o que enriquece a musicalidade e a dramaticidade do texto original.

O texto introdutório traz informações acerca da vida de Christopher Marlowe em um tom leve, próprio de seu autor, e identifica as questões principais relacionadas ao momento da composição e às particularidades e polêmicas atribuídas ao escritor. Uma breve história da obra e de sua recepção e ampliação na Europa marcam a ligação entre o texto introdutório e o posfácio assinado por Patrícia da Silva Cardoso, professora da Universidade Federal do Paraná. De cunho histórico-analítico, o posfácio discute, em um primeiro momento, a transforma- ção da condenação simples operada no texto anônimo editado por Spies para a tragédia desenvolvida por Marlowe em sua peça. Em um segundo momento, a autora traça um pequeno desenvolvimento da temática fáustica até Fernando Pessoa, autor que, tendo lido Marlowe e Goethe, leva o individualismo do (auto) conhecimento às últimas consequências, discutindo a própria capacidade de querer e de amar como construções intimamente humanas. Nota-se, na Tragédia Subjetiva de Pessoa, uma fragmentação completa, que se reflete também na própria forma do texto, do íntimo do ser, o que resvala por vezes em uma aporia niilista do pensamento que se arrasta até o limite do próprio conhecimento. O conhecimento da tradição fáustica é, portanto, essencial para a compreensão do drama pessoano, que carece de uma edição brasileira comentada, tendo em vista, assim como os textos fáusticos da tradição, a atualidade das discussões que são feitas na tragédia de Pessoa. ${ }^{2}$

A edição da Ateliê Editorial apresenta ao leitor também uma tradução, assinada por Mario Luiz Frungillo, do livro anônimo de Spies, que complementa a leitura da tragédia de Marlowe, ainda que o saibamos somente pela sinopse traseira do volume. Com um objetivo editorial diferente da edição de Magali Moura, a tradução de Frungillo, competente quanto a aspectos técnicos, apresenta o texto anônimo com uma quantidade menor de comentários e notas, o que, se por um lado permite uma leitura mais fluida da narrativa em si, por outro lado pode deixar leitores não especializados um tanto desamparados quanto a lugares, pessoas e acontecimentos mencionados no texto. Não prejudica, no entanto, o entendimento geral do texto, tendo 


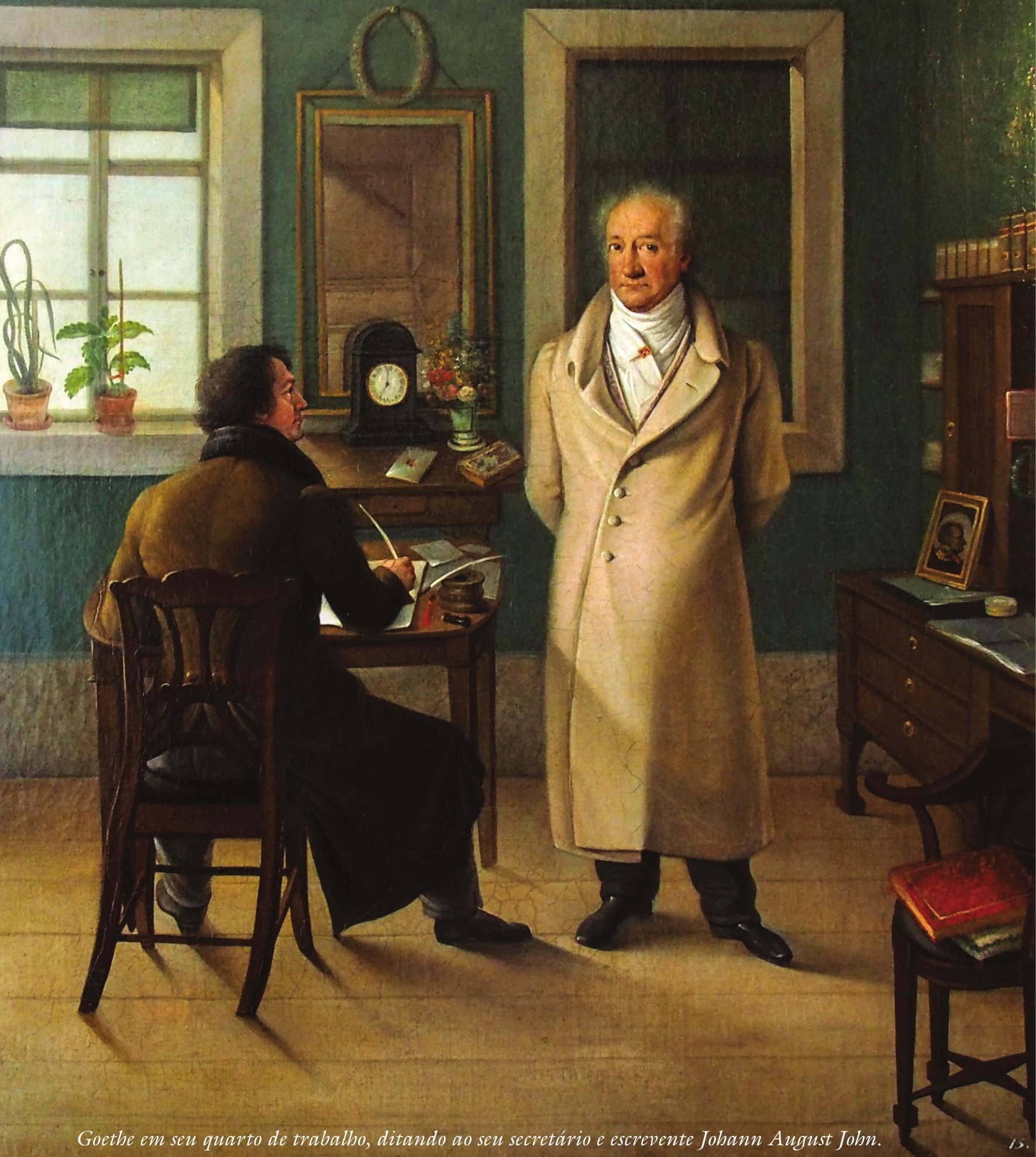

Goethe em seu quarto de trabalho, ditando ao seu secretário e escrevente Jobann August John. 
em vista que a própria obra original era destinada a leitores leigos, almejando um público mais amplo, o que se reflete na escolha da própria prosódia textual, da divisão em episódios claramente delimitados e na apresentação de questões religiosas de maneira clara e simples visando ao pronto entendimento; essas características textuais estão presentes e foram adotadas por Frungillo, conferindo uma fluidez à leitura do texto.

A edição também inclui um breve comentário sobre a tradução inglesa do Fausto, aquela em que Marlowe provavelmente se baseou para a escrita de sua própria peça. Optou-se por não apresentar uma tradução integral dessa obra, o que enriqueceria ainda mais a edição, mas somente o apontamento de algumas modificações do tradutor da obra para o inglês em relação ao texto publicado por Spies. Como as obras que tratam do tema fáustico estão felizmente sendo traduzidas ao português, uma versão também do Fausto inglês seria de grande valia para especialistas e entusiastas desse que é um dos principais mitos da moderna sociedade individual e individualista, nos termos de Ian Watt.

Circunscrito, em sua maior parte, a meios acadêmicos, o conhecimento das bases da tradição fáustica poderia esclarecer certas atitudes atuais e levar à reflexão o posicionamento do indivíduo em face à sociedade. É nesse sentido que se acolhe com entusiasmo a publicação dupla! - do texto original anônimo editado por Spies, aquele que deu início ao que virou uma longa e profícua tradição literária, e da competente tradução brasileira em versos da peça de Christopher Marlowe que, como esperam os tradutores, possa vir a se popularizar mediante sua encenação.

\section{Notas}

1 Não é redundante frisar esse ponto, pois que seria uma das maiores transformações pela qual passa o pensamento sobre Fausto. Segundo a autora: "Essa condenação peremptória da paixão de Fausto pelo saber tem sua raiz nos primeiros anos do cristianismo, por meio do filósofo Agostinho de Hipona (354-430), de cujas ideias Lutero se municiou para assentar a base de sua teologia, a qual, por sua vez, é a linha mestra que guiou o autor da História" (p.229). Pensando já sob a égide do Esclarecimento, Lessing, em um fragmento de Fausto, alteraria sobremaneira esse pensamento, já que, diante de um mundo que se pretende racionalista, condenar alguém pelo saber seria contraditório.

2 "Com tais linhas de força, o cenário em que se instala este Fausto [de Fernando Pessoa] é marcado pela melancolia e pelo desespero, devidamente repudiados pelo homônimo goetheano em sua aspiração solar" (p.483). Na História de 1587, conforme nos aponta Moura, a melancolia era ligada, especialmente por Lutero, a forças diabólicas; interessante notar a transformação para um Fausto puramente melancólico no início do século $\mathrm{XX}$, em que esse estado (tomando as lições de Starobinski em A tinta da melancolia) é a condição primeira da existência e do substrato dos pensamentos do Fausto pessoano.

\section{Referências}

ANÔNIMO. História do doutor Johann Fausto. Trad., notas e ensaio de Magali Moura. São Paulo: Filocalia, 2019.

DOSSIÊ GOETHE. Estudos Avançados. São Paulo, v.33, n.96, p.225-393. set./ dez. 2019.

MARLOWE, C. A trágica história do doutor Fausto. Org. e introdução de Luís Bueno. Trad. e notas de Luís Bueno, Ca- 
etano W. Galindo e Mário Luiz Frungillo. Posfácio de Patrícia da Silva Cardoso. São Paulo: Ateliê Editorial, 2018.

MAZZARI, M. V. A dupla noite das tílias: história e natureza no Fausto de Goethe. São Paulo: Editora 34, 2019.

Rafael Rocca dos Santos é mestre em Teoria Literária e Literatura Comparada pela Faculdade de Filosofia, Letras e Ciências Humanas da USP e doutorando em Estudos Literários e Culturais (LETRAS, literatura hebraica, FFLCH-USP).

@ - rocca@usp.br /

https://orcid.org/0000-0003-3783-1302

Recebido em 3.2.2020 e aceito em 2.3.2020.

I Faculdade de Filosofia, Letras e Ciências Humanas, Universidade de São Paulo, São Paulo, Brasil. 